\title{
Diagnostics of Periodontitis on the Basis of Spectral Analysis of the Rhythmic Activity of Brain
}

\author{
Polezhaeva Marina Aleksandrovnaํ, Mirgazizov Marzel Zakeevich², Shabanova Nina Geenadievna ${ }^{3}$, \\ Shabanov Gennadiy Anatolievich ${ }^{4}$
}

1Ph.D of Medical Sciences, Dental practitioner, Periodontist at the Innovative Dental Care Center "AIST", Okeansky Ave., Vladivostok, Russia.

${ }^{2}$ M.D., Honored Worker of Science of the Republic of Tatarstan, Professor at the Department of Clinical Dentistry and Implantology, "Institute of Advanced Studies of the Federal Medical and Biological Agency", Volokolamskoye Shosse, Moscow, Russia.

3Physiatrist at the Innovative Dental Care Center "AIST", Okeansky Ave., Vladivostok, Russia.

${ }^{4}$ Ph.D. of Biological Sciences, Associate Professor, Senior Research Scientist at Ecological Neurocybernetics Laboratory, Scientific Research Center “Arktika” Far Eastern Branch of RAS, Vladivostok-Magadan, Russia.

\section{ABSTRACT}

\section{BACKGROUND}

The development of diagnostic technologies for chronic generalized periodontitis (CGP) with the possibility of studying the pathogenesis of the disease and identifying its early signs is relevant. For the first time, the goal is to study the possibility of diagnosing, identifying specific signs and stages of development of CGP based on the registration of bioelectric activity of the brain.

\section{METHODS}

In patients with chronic generalized periodontitis (CGP), an analysis of the global cerebral bioelectrical activity was performed. A standard Neuron-Spectrum-1 electroencephalograph and a specialized narrow-band spectral analysis software in frequency range of 0.1 to $27 \mathrm{~Hz}$ and integration time of 160 seconds, allocation of 8400 spectral harmonics were used.

\section{RESULTS}

A number of distinguishing characteristics of electroencephalogram (EEG) spectrum envelope function was revealed in the studied patients, and 4 decisive characters were identified. For CGP, diagnostic Characters 1 and 2 marked by synchronization of hemispheres and significant pronounced decrease in the amplitude of the spectral estimate in frequency range of 0.91 to $0.95 \mathrm{~Hz}$ and 7.26 to $8.0 \mathrm{~Hz}$, were identified. Character 3 was associated with increased synchronization of hemispheres and increased amplitude of the spectral estimate in the frequency range of 3.72 to $4.03 \mathrm{~Hz}$. Hemispheric desynchronization in diagnostic Character 4 was detected in frequency range of 0.96 to $1.01 \mathrm{~Hz}$. The amplitude of spectrum asymmetry for Character 4 was specific to separate patients with CGP by severity levels.

\section{CONCLUSIONS}

The revealed changes in spectrograms are supposed to be used to clarify the pathogenesis, for early non-invasive diagnosis and to assess the severity of patients with CGP.

\section{KEY WORDS}

Periodontitis, cerebral bioelectrical activity, spectral analysis, decisive character

\section{Corresponding Author: Shabanova Nina Gennadievna, 53-62, Russkaya Str. Vladivostok, Russia-690049. \\ E-mail: ninashab22@gmail.com}

DOI: $10.14260 / \mathrm{jemds} / 2019 / 570$

Financial or Other Competing Interests: None.

How to Cite This Article: Aleksandrovna PM, Zakeevich MM, Geenadievna SN, et al. Diagnostics of periodontitis on the basis of spectral analysis of the rhythmic activity of brain. $J$. Evolution Med. Dent. Sci. 2019;8(33): 2617-2623, DOI: 10.14260/jemds/2019/570

Submission 16-01-2018, Peer Review 17-04-2019, Acceptance 24-04-2019, Published 19-08-2019. 


\section{BACKGROUND}

\section{BACKGROUND}

The current trend of research and development in periodontology is the objectification of the state of periodontium using the methods that could be applied in practice for early disease detection, consideration of the pathological condition from a systemic point of view, prediction and effective treatment of patients. ${ }^{1,2}$

At present, along with the main examination methods, some additional methods are used and they allow to describe in full the severity of any pathological process in periodontium. ${ }^{3}$ Among them, functional research methods are extensively used, namely, reoparodontography (RPG), photoplethysmography (PPG), biomicroscopy, polarography, laser doppler flowmetry (LDF), and many others.

It should be noted that there is practically no data in the literature concerning the relation between periodontitis and cerebral bioelectric activity. It is known that the central nervous system (CNS) controls and integrates into a whole a variety of physiological functions of the body, contains mechanisms for analyzing and correcting functional disorders, and carries the possibilities of representing and adjusting the visceral sphere of various organs. ${ }^{4,5,6}$ Numerous studies have shown that nonspecific reticular structures of the brain create the diffuse "background" rhythmic activity which determines the unified functional state of the cerebral cortex and effector organs.7,8,9,10,11,12 There are a number of reviews concerning the connection of brain rhythms and functional state of the body in various general and local pathological processes. ${ }^{4,13,14}$ We believe that application of the proposed method in combination with the main diagnostic techniques should extend to the interpretation of the clinical features of any pathological process and it would increase the level of diagnostics of the disease, and determine the best strategy for treatment and prevention of periodontitis.

Purpose of the study was to study the possibility of diagnosing chronic generalized periodontitis (CGP), identifying specific diagnostic signs and the degree of CGP severity based on the recording of spectral analysis of the bioelectric activity of the brain.

\section{METHODS}

Technology for the diagnosis of CGP using bioelectrical activity of the brain was developed for the first time. The study was formed on the basis of the requirements for the "training" project: a preliminary study to evaluate the new technology, to highlight statistically significant diagnostic features, to prepare the project for more extensive research. Two groups of subjects-patients (136 patients) and control (58 people)- were selected without any random pre-selection processes. The number of patients (n) in the group was calculated based on the criteria for population studies 15 , taking into account p-estimated prevalence of CGP in the population (15\%); $\mathrm{t}-$ the desired level of research accuracy (95\%); m-limit of permissible error (5\%).
The inclusion criterion was the presence in patients of varying severity of clinical manifestations of chronic generalized periodontitis (CGP), who applied for periodontal care in the Innovative Dental Center "AIST" in Vladivostok (Table 1).

The exclusion criteria for the groups were refusal to sign informed consent to the survey, not understanding the explanations of the research being conducted.

The study included 136 patients aged 22-65 with the clinical signs of chronic generalized periodontitis (CGP) of various severity, who sought the periodontal attention at Innovative Dental Care Center "AIST" in Vladivostok (Table 1). The control group consisted of 58 conditionally healthy patients, namely 32 women and 26 men without any visible periodontal pathology. Informed consent for the examination was obtained from all the patients. The minimum number of patients in the groups was calculated from the principle of stratified sampling and criteria of occurrence of pathological conditions in the groups.

The comprehensive study included an interview, examination, history taking, recording of rhythmic activity of brain, conducting a clinical dental examination using the Florida Probe Diagnostic System (USA), determining the need for treatment of periodontal disease (CPITN), simplified oral hygiene index (OHI-s), JC Green, JR Vermillion, SchillerPisarev samples, as well as X-ray examination, namely orthopantomography or 3D computer tomography. A physical examination of oral cavity showed the dental occlusion features, the condition of tongue and lip frenulum, the condition of the existing filling material, and orthopedic structures. When examining the gingival mucosa, the gum color, line and consistency, the presence and nature of any dental deposits, the presence of gingival bleeding and swelling (cyanoticity), the presence of gingival recessions, the degree of tooth loosening have been evaluated. Based on the examination of patients by classical methods, from the group of 136 patients, three subgroups were selected according to the severity of CGP development - 1,2,3 clinical forms of CGP. ${ }^{16,17}$

The analysis of the cerebral bioelectrical activity was performed using the standard Neuron-Spectrum-1 electroencephalograph and a specialized software package for spectral analysis of the rhythmic activity of a human brain as designed for medical application for the purpose of early detection of any pathologies in internal organs. The technology of recording the "global" rhythmic activity of brain, spectral analysis of signal with the narrow-band filtering $(8,400$ frequency harmonics) and long integration time (160 sec) was applied. The electrodes were placed at temporoparietal leads, on both sides symmetrically. Such technology made it possible to identify primarily long-lasting, sustainably active rhythmic components in frequency range of 0.1 to $27 \mathrm{~Hz}^{4,13}$ With this method of analysis, the frequency profile of oscillating elements of nonspecific reticular brain structures (activating system of the brain) was assessed as a source of ascending and descending tonic activity that forms the functional state of various effectors or reflex groups, mainly of visceral sphere. The oscillatory structure has the frequency specificity for monitoring each type of interoreceptors. ${ }^{9,4,5}$ Based on this feature, the frequency range was transformed into a frequency matrix such as "a set of functional states" or "viscera" which turned out to be 
convenient for detecting any disorders and diseases of internal organs, including those of the dentition system. ${ }^{2}$ The coordinate system of the matrix was represented by 24 volumes or segments of the body along the ordinate axis, and visceral receptor modality along the abscissa axis ( 7 groups each of 25 modes). 4,13

Mathematical processing of the results was carried out using the statistical software package Statistica 6.1. The normality of the traits was checked using the KolmogorovSmirnov criterion. The valuation methods of the program "Statistica 6.1" were applied to parameters with abnormal distribution. Quantitative signs were presented as mean value (Mean), standard quadratic deviation (Std. Dev.). For comparison of groups, the Student criterion was used under the condition that the variances of the independent comparison groups according to the Leuven criterion are equal ( $\mathrm{t}$-test, $\mathrm{p} \leq 0.05)$.

\section{RESULTS}

In the result of the spectral analysis of cerebral rhythmic activity and comparison of the spectrograms of healthy persons and patients, 4 statistically significant characters were identified.

Fig. 1 represents F5 function graphs displaying the envelopes of frequency spectrum of the right and left hemispheres. The value of the spectral estimate was expressed in relative units $\mathrm{Ai}$ on the ordinates scale from 0 to 1.0 relative units. The scale of ordinates on the right side displays 24 volumes, i.e. frequency ranges of 0.13 to $27 \mathrm{~Hz}$, notionally named as "segments" from C1 to K-S5. With the summation of the 1,2, 3 groups of patients with CGP of various severity, diagnostic Character 1 was identified, and it was characterized by abnormal C4-5-6 segments, 5-3-2 through 5-3-3 function in frequency range of 0.91 to $0.95 \mathrm{~Hz}$ with the minimum amplitude Ai of the spectrum from 0.032 to 0.016 relative units $(p \leq 0.05)$. The Character was determined only for graphs of the left hemisphere (dash line).

Diagnostic Character 2 (Fig. 2) was featured with a pronounced decrease in the amplitude of the spectral estimation of F2-2-4 to 2-3-3 functions for C4-5-6 segments to values $\mathrm{Ai}=0,062-0,047$ relative units $(\mathrm{p} \leq 0.05)$. The frequency range was from 8.0 to $7.26 \mathrm{~Hz}$. Character 2 was determined only for graphs of the left hemisphere (dash line). Diagnostic Character 3 for the same segments was detected on 3-2-5 to 3-3-2 functions in frequency interval of 4.03 to $3.72 \mathrm{~Hz}$. The amplitude of the spectrum envelopes was in the confidence interval of 0.4 to 0.8 relative units. $(\mathrm{p} \leq 0.05)$. Character 3 was determined for both left and right hemispheres in the form of synchronization of the spectrum envelopes.

Diagnostic Character 4 (Fig. 3) appeared to be specific for the division of the 1, 2, 3 groups of CGP by severity level. In case of any inflammatory process in Th12 segment, there was a pronounced asymmetry of the spectral relief, the right branch of the spectrum envelope graphs prevailed over the left one. The frequency range was 0.96 to $1.01 \mathrm{~Hz}$. The severity of CGP was associated with the intensity of the amplitude difference between right and left branches of the graphs (4A, 4B, 4C Characters). For CGP of minor severity (A), the difference was $0.21 \pm 0.14$ relative units; with moderate severity (B) $-0.35 \pm 0.15$ relative units; with major severity (C) $-0.78 \pm 0.37$ relative units.

For a group of healthy persons, the spectral estimate amplitude of the Character 1 was in the confidence interval of 0.05 to 0.21 relevant units $(\mathrm{p} \leq 0.05)$. The amplitude of Character 2 was in the confidence interval of 0.09 to 0.25 relevant units $(\mathrm{p} \leq 0.05)$. The amplitude of Character 3 was in the confidence interval of 0.1 to 0.35 relevant units ( $p \leq 0.05)$. Character 4 for a group of healthy persons was significantly different from the group of patients with the predominance of not the right but the left branch of the spectral envelope of the graphs in spectral regions F5-5-1....5-5-3. Therefore, the difference between right and left branches (R-L) was equated to zero. In sick patients, the difference in the prevalence of the right branch of the graphs over the left one was for different degrees of severity in 0.21 to 0.78 relative units.

\section{DISCUSSION}

Using generally accepted methods of diagnosing CGP (Table 2), patients were divided into 3 groups according to the severity of the disease $(16,17)$

- $\quad$ CGP of minor severity - 36 people;

- $\quad$ CGP of moderate severity - 52 people;

- $\quad$ CGP of major severity - 48 people.

The control group with no signs of disease was 58 people.

In connection with the goal of the research, two main tasks were solved-

1. To find signs of differences in the EEG spectrum of the examined patients between the control group and the group of patients with CGP.

2. To find in the EEG spectrum of the examined patients signs of differences in the subgroups of patients with CGP by severity.

Character 1 was detected as a depression of the left hemisphere rhythm in the frequency range from 0.91 to 0.95 $\mathrm{Hz}$ with amplitude Ai from 0.032 to 0.016 relative unit. In this case, Ai was $0.13 \pm 0.06$ in the control group in this frequency range. Character 1 reliably distinguished patients with CGP and a control group.

Similarly, Character 2 and Character 3 found in the frequency ranges $7.26-8.0 \mathrm{~Hz}$ and $3.72-4.03 \mathrm{~Hz}$, respectively, reliably distinguished patients with CGP and the control group (see Table 3).

Characters 1, 2, 3 did not show a reliable allocation of subgroups according to the severity of CGP. These characters should be used as markers for the presence of CGP. The reliability of differences between groups of patients and healthy for each decision rule was statistically confirmed. Student's criterion was used under the condition that the variances of the comparison groups were equal according to the Leuven criterion. On the basis of the confidence coefficient $t$ using the number of degrees of freedom or the number of observations, the error probability coefficient $(\mathrm{p})$ was determined using the Student-Fisher tables and was $\mathrm{p} \leq 0.05$. 
It can be seen from table 3 that the group of healthy people differs from CGP patients by a significant difference in the amplitudes of the spectral assessment of Characters 1-3 and the predominance of the spectral activity of the right hemisphere of the brain over the left according to Character 4. The more prevalent is the activity of the right hemisphere (from 0.21 to 0,78 relative units) in the spectral region of $0.96-1.01 \mathrm{~Hz}$, according to Symptom 4, the higher is the severity of CGP. Based on these estimates, each of the characters was assigned a weight, which is displayed in the conclusion when the specified thresholds are exceeded. Depending on the total weight of the rules, a conclusion was made about the presence or risk of developing periodontitis, the severity of CGP. With the increase in patient groups, the task is to correlate the total weight of the rules with the severity of CGP development.

Long-term monitoring of a group of healthy people who have no complaints ( 58 people) showed that there are a small number of people who only occasionally showed Symptom $4 \mathrm{~A}$, in the absence of Symptoms 1-3 (11 people or $20 \%$ ). An in-depth examination of the latter (Schiller-Pisarev positive test $-2.9 \pm 0.14$, OHI-s hygiene index (Green-Vermilion) - 1.6 \pm 0.09 ) allowed us to create a risk group for CGP.

It should be noted that for a deeper understanding of the pathogenesis of periodontitis development in the light of the neurotrophic concept of regulation of organs and tissues from the central nervous system based on the studies conducted by the authors $5,10,11,12$ it may be assumed that-

- Character 1 is represented by reflexes of the Mcholinergic receptor system of connective and bone tissues of teeth;

- Character 2 is reflexes of the alpha-adrenergic receptor system of arterial vessels of teeth;

- $\quad$ Character 3 is reflexes of the alpha-adrenergic receptor system of venous vessels of the teeth;

- Character 4 is reflexes of the M-cholinergic receptor system of aldosterone metabolism chains of the right kidney.

We showed that when comparing the groups of patients having the various severity of clinical signs of chronic generalized periodontitis (136 patients) and conditionally healthy persons without any visible periodontal pathology (58 patients), based on the presence of Characters $1,2,3,4$, the software recognized CGP with a sensitivity of 0.82 and a specificity of 0.75 .

\begin{tabular}{|c|c|c|c|}
\hline No. & Clinical Forms of CGP & n, Women/Men & Age (Years Old, M/m) \\
\hline 1 & CGP of minor severity & $36(20 / 16)$ & $22,5 \pm 5,5$ \\
\hline 2 & CGP of moderate severity & $52(27 / 25)$ & $32,0 \pm 7,0$ \\
\hline 3 & CGP of major severity & $48(20 / 28)$ & $41,5 \pm 6,5$ \\
\hline Table 1. Classification of Patients by Groups, Nosological Forms of CGP, \\
Gender and Age \\
\hline
\end{tabular}

\begin{tabular}{|c|c|c|c|c|}
\hline Groups & $\begin{array}{l}\text { CGP of Minor } \\
\text { Severity }\end{array}$ & $\begin{array}{c}\text { CGP of } \\
\text { Moderate } \\
\text { Severity }\end{array}$ & $\begin{array}{c}\text { CGP of Major } \\
\text { Severity }\end{array}$ & Control \\
\hline $\begin{array}{c}\text { Clinical } \\
\text { examination } \\
\text { Florida Probe: } \\
\text { - depth of } \\
\text { periodontal } \\
\text { pockets (PS) } \\
\text { - bleeding gums } \\
\text { - teeth mobility } \\
\text { - PIRI }\end{array}$ & $\begin{array}{c}\leq 3,5 \pm 0,2 \mathrm{~mm} \\
\leq 15 \pm 4,8 \% \\
\text { No } \\
\leq 0,8 \pm 0,3\end{array}$ & $\begin{array}{c}\leq 4,2 \pm 0,5 \mathrm{~mm} \\
\leq 28 \pm 5,6 \% \\
\text { I-II degree } \\
\leq 3,6 \pm 0,5\end{array}$ & $\begin{array}{c}\leq 6,2 \pm 1,8 \mathrm{~mm} \\
\leq 58 \pm 7,6 \% \\
\text { II degree } \\
\leq 6,0 \pm 0,1\end{array}$ & $\begin{array}{c}\leq 1-2 \mathrm{~mm} \\
\text { No } \\
\text { No } \\
-\end{array}$ \\
\hline Index CPITN & 2 points & 2-3 points & 3-4 points & 0 points \\
\hline $\begin{array}{c}\text { Index } \\
\text { OHI-s (Green } \\
\text { Vermillion) - } \\
\end{array}$ & $1,6 \pm 0,09$ & $2,0 \pm 0,07$ & $2,2 \pm 1,34$ & 0 points \\
\hline $\begin{array}{c}\text { Schiller-Pisarev } \\
\text { test } \\
\end{array}$ & $2,9 \pm 0,14$ & $3,2 \pm 0,19$ & $3,9 \pm 1,25$ & Negative \\
\hline $\begin{array}{c}\text { X-ray } \\
\text { examination } \\
\text { (OPTG. CT) }\end{array}$ & $\begin{array}{l}\text { Resorption of } \\
\text { vertices of } \\
\text { interalveolar septa } \\
\text { from } 1 / 4-1 / 3 \text { of } \\
\text { the length of the } \\
\text { roots of the teeth }\end{array}$ & \begin{tabular}{|c|} 
Resorption of \\
vertices of \\
interalveolar \\
septa from $1 / 3-$ \\
$1 / 2$ of the length \\
of the tooth \\
roots
\end{tabular} & $\begin{array}{c}\text { Bone resorption of } \\
\text { the alveolar } \\
\text { processes of the } \\
\text { upper and lower } \\
\text { jaw from } 1 / 2-2 / 3 \\
\text { tooth roots }\end{array}$ & $\begin{array}{c}\text { No change } \\
\text { in } \\
\text { radiograph }\end{array}$ \\
\hline
\end{tabular}

Table 2. Criteria for The Separation of Patients with CGP into Groups According to Severity Obtained Using Standard Equipment.

(Mean $\pm 2 S D)$

\begin{tabular}{|c|c|c|c|c|}
\hline Groups Criteria & $\begin{array}{l}\text { CGP of Minor } \\
\text { Severity Ai }\end{array}$ & $\begin{array}{c}\text { CGP of } \\
\text { Moderate } \\
\text { Severity Ai }\end{array}$ & \begin{tabular}{|c|} 
CGP of \\
Major \\
Severity \\
Ai \\
\end{tabular} & $\begin{array}{c}\text { Control } \\
\text { Ai }\end{array}$ \\
\hline $\begin{array}{c}\text { Character } 1 \\
\text { C4-6/ 5-3-2 (L) } \\
0.91-0.95 \mathrm{~Hz}\end{array}$ & $0,032 \pm 0,013$ & $0,027 \pm 0,015$ & $\begin{array}{c}0,016 \pm \\
0,009\end{array}$ & $\begin{array}{c}0,13 \pm \\
0,06\end{array}$ \\
\hline $\begin{array}{c}\text { Character } 2 \\
\text { C4-6/2-2-4(L) } \\
\text { 7,26-8,0 Гц }\end{array}$ & $0,062 \pm 0,031$ & $0,051 \pm 0,027$ & $\begin{array}{c}0,047 \pm \\
0,022\end{array}$ & $\begin{array}{c}0,17 \pm \\
0,08\end{array}$ \\
\hline $\begin{array}{l}\text { Character } 3 \\
\text { C4-6/ 3-2-5 } \\
3.72-4.03 \mathrm{~Hz} \\
\end{array}$ & $0,47 \pm 0,18$ & $0,52 \pm 0,21$ & $0,64 \pm 0,27$ & $0,22 \pm$ \\
\hline $\begin{array}{c}\text { Character 4A } \\
\text { C4-6/ 5-5-1 } \\
0.96-1.01 \mathrm{~Hz} \mathrm{0,96-1,01} \mathrm{Гц}\end{array}$ & $\begin{array}{l}0,21 \pm 0,14 \\
\mathrm{R}>\mathrm{L}\end{array}$ & & & $0 \mathrm{~L}>\mathrm{R}$ \\
\hline $\begin{array}{c}\text { Character 4 B } \\
\text { C4-6/ 5-5-1 } \\
0.96-1.01 \mathrm{~Hz}\end{array}$ & & $\begin{array}{l}0,35 \pm 0,15 \\
\quad \mathrm{R}>\mathrm{L}\end{array}$ & & $0 \mathrm{~L}>\mathrm{R}$ \\
\hline $\begin{array}{c}\text { Character 4 C } \\
\text { C4-6/ 5-5-1 } \\
0.96-1.01 \mathrm{~Hz}\end{array}$ & & & $\begin{array}{l}0,78 \pm 0,37 \\
\quad \mathrm{R}>\mathrm{L}\end{array}$ & $0 \mathrm{~L}>\mathrm{R}$ \\
\hline \multicolumn{5}{|c|}{$\begin{array}{l}\text { Table 3. Characters Identified by Spectral Analysis of Bioelectric } \\
\text { Activity of The Brain for Different Subgroups According to The }\end{array}$} \\
\hline
\end{tabular}



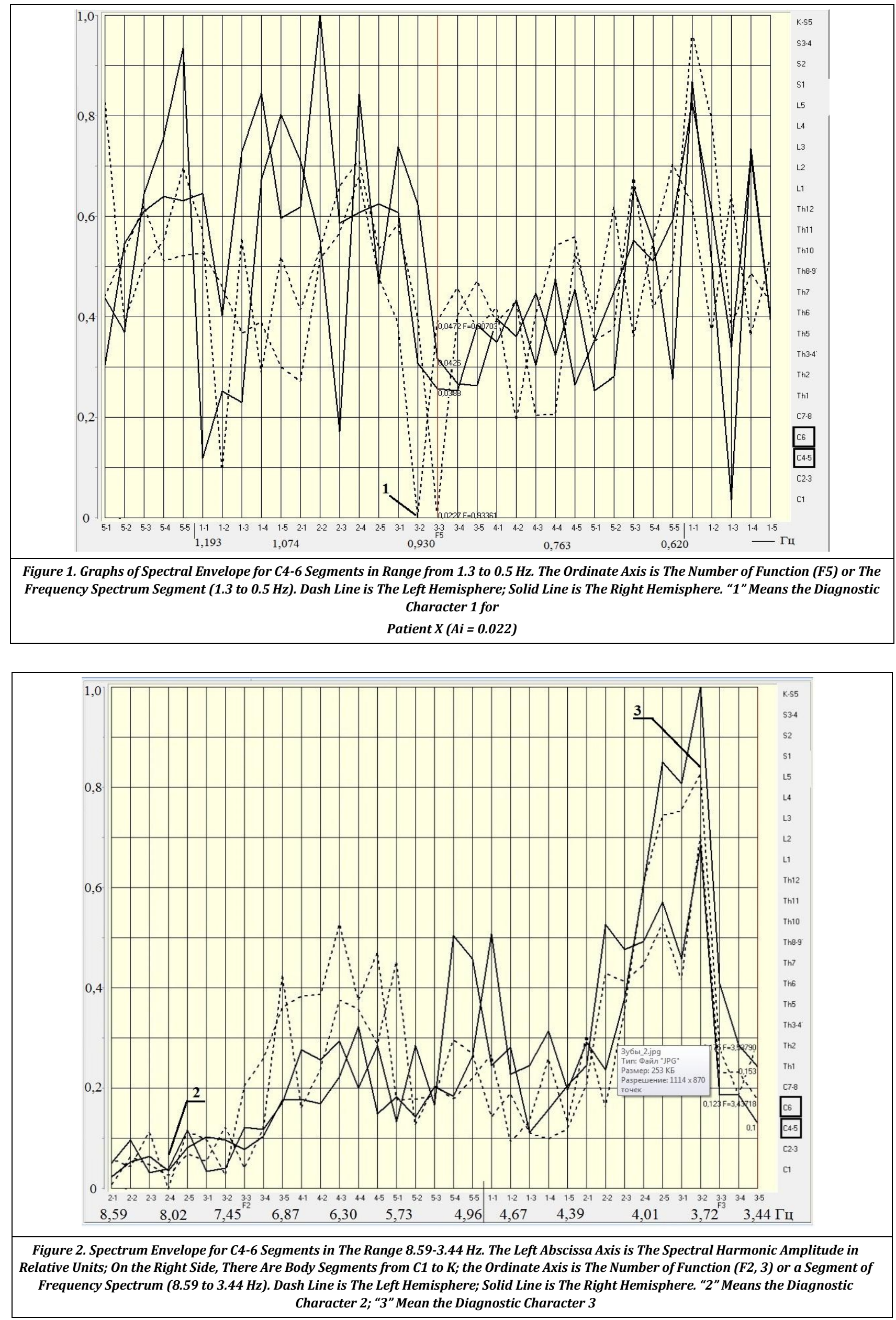


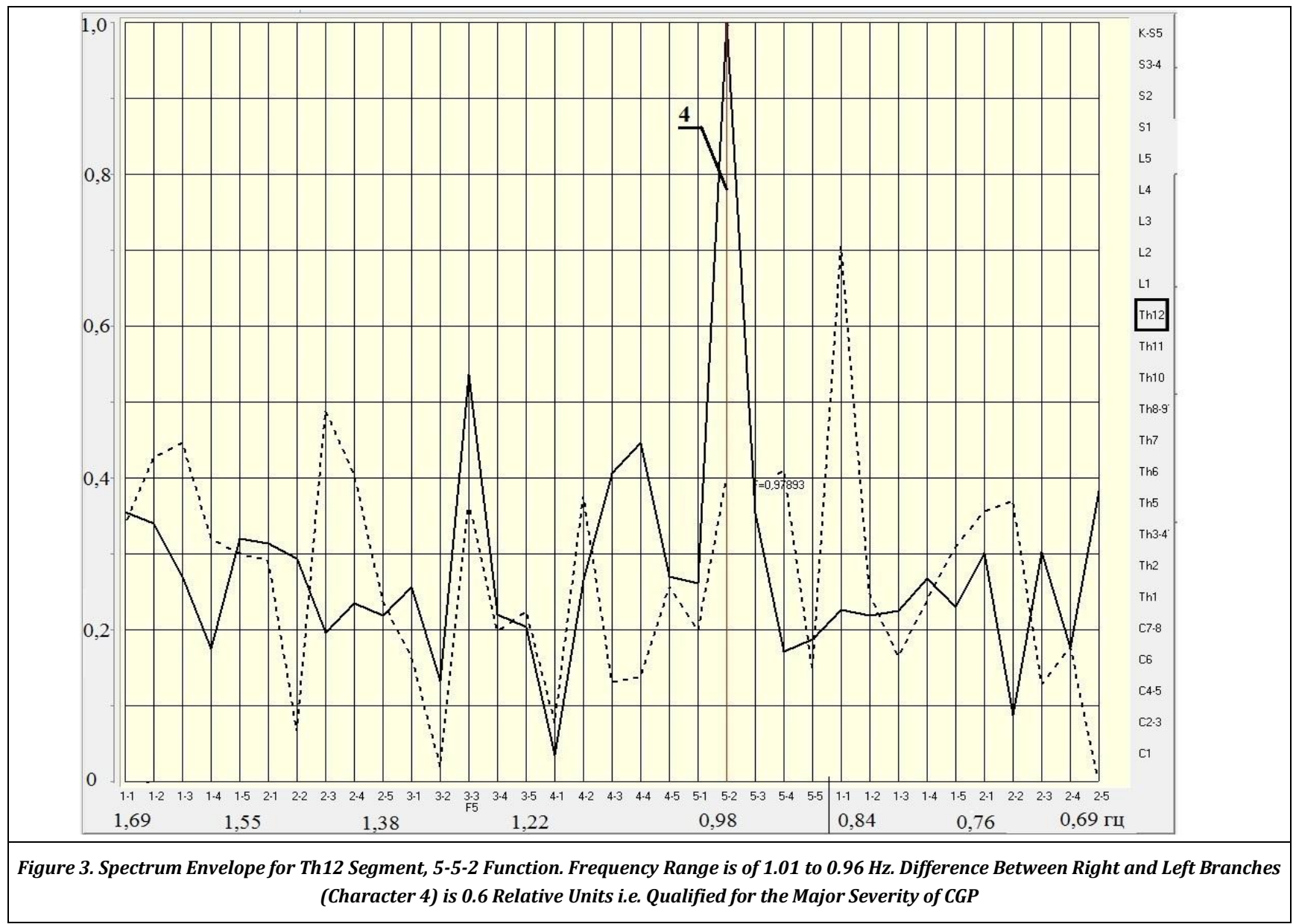

\section{List of Abbreviations}

Min S- Minor Severity

Mod S- Moderate Severity

Maj S- Major Severity

OPG- Orthopantomography

CGP- Chronic Generalized Periodontitis

EEG- Electroencephalogram

\section{CONCLUSION}

Therefore, the spectral analysis of rhythmic brain activity in the frequency range from 0.1 to $27 \mathrm{~Hz}$, highlighting 8400 spectral harmonics with integration time of 160 seconds definitely showed that when a patient has any signs of chronic generalized periodontitis, the spectral bands appear in the rhythmic activity spectrum of EEG with increased hemispheric synchronization and abnormally low amplitude of the spectral estimate $\mathrm{Ai}$ in frequency ranges of 0.91 to 0.95 $\mathrm{Hz}, 8.0$ to $7.26 \mathrm{~Hz}$, and increased amplitude of the spectral estimate $\mathrm{Ai}$ in range of 3.72 to $4.03 \mathrm{~Hz}$. The degree of desynchronization and the asymmetry amplitude of the spectral estimate of the range of $0.96-1.01 \mathrm{~Hz}$ turned out to be related to the severity of CGP. The data obtained allows to determine the risk of developing periodontitis, diagnose various forms according to the severity of chronic generalized periodontitis, clarify the pathogenesis of the disease, which can lead to some success in the tactics of treatment of this pathology.
A preliminary, "educational" study showed that a new diagnostic method for spectral analysis of the bioelectric activity of the brain gave positive results. Further large-scale studies with larger samples are needed.

\section{REFERENCES}

[1] Barer GM. Periodontal disease. Clinical findings, diagnostics and treatment. Tutorial 1996: p. 85.

[2] Kononov VN, Shabanov GA, Shabanova NA. Method of diagnosing the condition of internal organs. Patent No. 2317002, priority dated 22.05.2006. Application No. 2006117646. Published on 20.02.2008. Bulletin No. 5.

[3] Ivanov VS. Periodontal diseases. Moscow: Medical Information Agency 1998: p. 67-70.

[4] Shabanov GA, Maksimov AL, Rybchenko AA. The functional and topical diagnostics of human organism on the basis of analysis of cerebral rhythmic activity. Vladivostok: Dal'nauka 2011: p. 206.

[5] Shabanov GA, Rybchenko AA, Maksimov AL. The activating system model of brain potential spatial organization: theoretical and experimental study. Bulletin of the North-Eastern Research Center of the Far Eastern Branch of the RAS 2005;1:49-56.

[6] Shepovalnikov AN, Ciceroshin MN, Pogosian AA. About some principles of integration of bioelectric activity of spatially distributed parts of neocortex into the entire 
dynamic system. Fiziol Cheloveka Human Physiology 1995;21(5):36-50.

[7] Bursian AV. Pacemakers of visceral systems. Usp Fiziol Nauk Advances in Physiological Sciences 2008;39(4):3-13.

[8] Vagramyan ZA. Oscillatory neural network in the closed systems of the brain. Bulletin of the Russian Armenian University. Physics, Mathematics and Natural Sciences 2008;1:102-7.

[9] Fedotchev AI, Bondar' AT, Akoev IG. The rhythmic structure of human EEG: the modern state and investigative trends. Advances in Physiological Sciences 2000;31(3):39-53.

[10] Basar E, Basar-Erpglu C, Karakas S, et al. Brain oscillations in perceptions and memory. Int J Psychophysiol 2000;35(2-3):95-124.

[11] Basar E. The theory of the whole-brain-work. Int J Psychophysiol 2006;60(2):133-8.

[12] Buzski G, Drguhn A. Neuronal oscillations in cortical networks. Science 2004;304(5679):1926-9.

[13] Shabanov GA, Rybchenko AA. The spectral analysis of cerebral rhythmic activity in topical diagnostics of internal organs diseases. The $18^{\text {th }}$ Convention of I. P.
Pavlov Physiological Association. Kazan, 2001: p. 2689.

[14] Cantero JL, Atienza M, Gomez C, et al. Spectral structure and brain mapping of human alpha activities in different arousal states. Neuropsychobiology 1999;39(2):110-6.

[15] Koychubekov BK, Sorokina MA, Mkhitaryan KE. Determination of sample size in the planning of scientific research. International Journal of Applied and Fundamental Research No 4. 2014: p. 71-4.

[16] Sorokina MA. Development and evaluation of the effectiveness of indications for surgical methods of treatment of periodontal diseases. The author's abstract of thesis... Ph.D of Medical Sciences Voronezh: 2012: p. 24.

[17] Sorokina MA. Identifying the viability of the gingival mucosa and its role in the diagnosis and treatment of periodontal diseases. Bulletin of new medical technologies, Tula, T. 18, 2011;2:219-22. 